Document downloaded from:

http://hdl.handle.net/10251/68853

This paper must be cited as:

Vaca Puga, A.; Teixidor, F.; Kivekas, R.; Sillanpaa, R.; Viñas, C. (2006). A solvent-free regioselective iodination route of ortho-carboranes. Dalton Transactions. (41):4884-4885. doi:10.1039/b612465h.

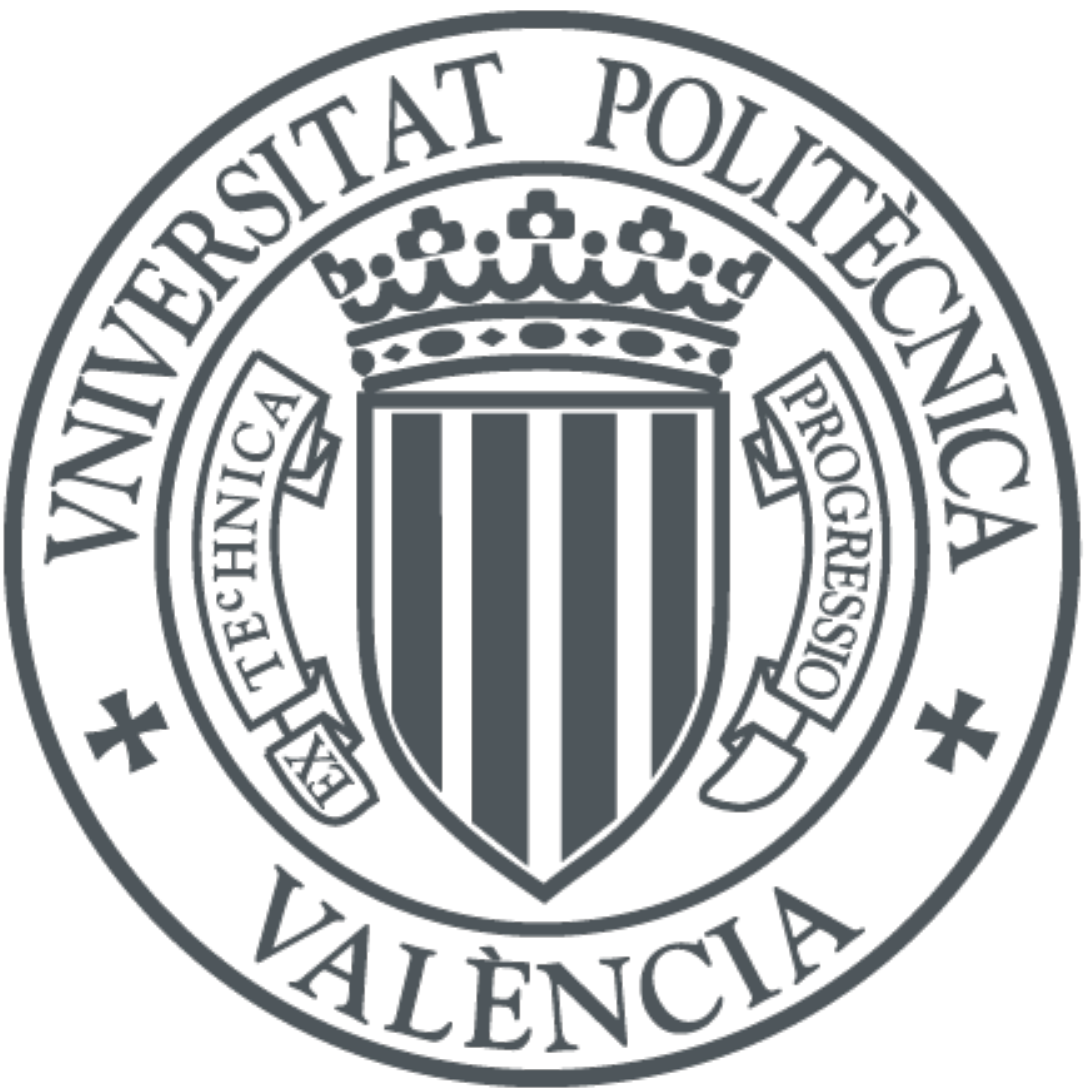

The final publication is available at

http://dx.doi.org/10.1039/b612465h

Copyright Royal Society of Chemistry

Additional Information 


\title{
A solvent-free regioselective iodination route of ortho-carboranes
}

\author{
Albert Vaca, ${ }^{a, b}$ Francesc Teixidor, ${ }^{a}$ Raikko Kivekäs, ${ }^{\mathrm{c}}$ Reijo Sillanpääd ${ }^{\mathrm{d}}$ and Clara Viñas ${ }^{\mathrm{a}, *}$ \\ Receipt/Acceptance Data [DO NOT ALTER/DELETE THIS TEXT] \\ Publication data [DO NOT ALTER/DELETE THIS TEXT] \\ 5 DOI: 10.1039/b000000x [DO NOT ALTER/DELETE THIS TEXT]
}

Tetraiodo-ortho-carborane based $\mathrm{X}$-ray contrast agents can be readily produced in a high yield, fast, clean, regioselective fashion by a solvent-free reaction of ortho-carboranes with iodine in sealed tubes.

10 The quest for more efficient and environmentally friendly transformations is nowadays essential for the sustainability of chemical synthesis in the $21^{\text {st }}$ century. ${ }^{1}$ In this line, an excellent solution is the replacement of volatile organic solvents for alternative reaction media, mainly supercritical fluids, ionic liquids,

15 water or absence of a solvent. ${ }^{2}$ The latter option is the best known of them, widely employed in petrochemical industry with remarkable waste minimization. ${ }^{2}$ Despite such advantages, only recent advances in solventless solid-state reactions are showing the ability to selectively produce high value substances, providing

20 successful results in organic and organometallic synthesis. ${ }^{3}$

Highly iodinated molecular species receive great interest in medical applications ${ }^{4}$ and materials science. Highly iodinated ortho-carboranes with metal-based X-ray contrast agents, ${ }^{5}$ are called to be a new generation of advanced radiopaques for clinical

25 purposes. They represent a great increase in iodine percentage by weight compared to the iodinated organic compounds used in $\mathrm{X}$ ray contrast agents. Clean and effective synthetic methods are still the critical issue for the consideration of highly iodinated orthocarboranes as promising candidates for X-ray diagnosis. ${ }^{6}$

30 ortho-Carborane, 1,2- $\mathrm{C}_{2} \mathrm{~B}_{10} \mathrm{H}_{12}$, and its derivatives, have been typically iodinated under electrophilic conditions, requiring the use of Lewis or Brönsted acid catalysts. Thus, three methods have been developed for the transformation of B-H vertices to B-I ones: i) elemental iodine in the presence of alumminum trichloride ${ }^{7}$ or a

35 mixture of acetic, nitric and sulfuric acids to yield diiodinated compounds, ${ }^{8}$ ii) iodine monochloride and triflic acid to transfrom eight B-I vertices ${ }^{6 a}$ and recently, iii) a sequential combination of nucleophilic and electrophilic reactions to generate the highest boron iodinated ortho-carboranes: 3,4,5,7,8,9,10,11,12-I9-closo- 80

$401,2-\mathrm{C}_{2} \mathrm{~B}_{10} \mathrm{H}_{3}$ and $3,4,5,6,7,8,9,10,11,12-\mathrm{I}_{10}-1,2$-closo- $\mathrm{C}_{2} \mathrm{~B}_{10} \mathrm{H}_{2}{ }^{9}{ }^{9}$ Their extremely high iodine content (around 90\%), should make them of interest to build new high performance X-ray contrast agents, but complications in the synthetic route are still a problem.

This work aims at establishing new competitive preparations of 85

45 polyiodinated ortho-carboranes in the absence of any solvent. Our

\footnotetext{
a I.C.M.A.B. (C.S.I.C.),Campus U.A.B., 08193 Bellaterra, Spain. Fax: 34 3580 5729; Tel: 343580 1853; E-mail: clara@icmab.es

${ }^{b}$ Albert Vaca is enrolled in the PhD program of the UAB.

${ }^{c}$ Department of Chemistry, P.O. Box 55, University of Helsinki, FIN00014 Helsinky, Finland

${ }^{d}$ Department of Chemicstry, University of Jyväskylä, FIN-40351

Jyväskylä, Finland

$\uparrow$ Electronic Supplementary Information (ESI) available: [Synthesis and characterization of 1-5.]. See http://dx.doi.org/10.1039/b000000x/
}

strategy aims at exploring the reactivity of ortho-carboranes with $\mathrm{I}_{2}$ under thermal treatment in sealed tubes, but in the absence of any strong acid, in order to attain cleaner and more practical pathways for neutral molecular inorganic X-ray contrast agents.

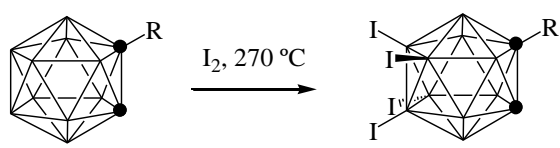

55 Scheme 1 General tetraiodination of 1-R-1,2-closo $-\mathrm{C}_{2} \mathrm{~B}_{10} \mathrm{H}_{11}$ by reaction with iodine in sealed tubes. For $\mathrm{R}=\mathrm{H}, \mathrm{t}=4 \mathrm{~h}$. For $\mathrm{R}=\mathrm{Me}$ or $\mathrm{Ph}, \mathrm{t}=3.5 \mathrm{~h}$.

Regioselectively tetraiodinated ortho-carborane 8,9,10,12-I $\mathrm{I}_{4}-1,2-$ closo- $\mathrm{C}_{2} \mathrm{~B}_{10} \mathrm{H}_{8}(\mathbf{1})$ was easily obtained in a solvent-less reaction just 60 by heating 1,2-closo- $\mathrm{C}_{2} \mathrm{~B}_{10} \mathrm{H}_{12}$ with four equivalents of $\mathrm{I}_{2}$ at $270 \pm 2$ ${ }^{\circ} \mathrm{C}$ for 24 hours in a sealed tube. After the reaction is complete, the Pyrex tube is opened and gaseous $\mathrm{IH}$ is immediately evaporated leaving a solid. The crude product contained $\mathrm{ca}$. $25 \%$ of $8,9,12-\mathrm{I}_{3}-$ 1,2-closo- $\mathrm{C}_{2} \mathrm{~B}_{10} \mathrm{H}_{9}$ and $75 \%$ of $8,9,10,12-\mathrm{I}_{4}-1,2$-closo- $\mathrm{C}_{2} \mathrm{~B}_{10} \mathrm{H}_{8}$, 65 based on ${ }^{1} \mathrm{H}\left\{{ }^{11} \mathrm{~B}\right\}$ NMR spectroscopy. Longer reaction times did not improve substantially this result. Experiments with higher iodine ratio were indeed much quicker and more selective; heating 1,2-closo- $\mathrm{C}_{2} \mathrm{~B}_{10} \mathrm{H}_{12}$, now with ten equivalents of $\mathrm{I}_{2}$ at $270 \pm 2{ }^{\circ} \mathrm{C}$ for 4 hours in a sealed tube produced a solid containing $\mathrm{ca}$. $93 \%$ of $708,9,10,12-\mathrm{I}_{4}-1,2-$ closo- $\mathrm{C}_{2} \mathrm{~B}_{10} \mathrm{H}_{8}, 2 \%$ of 8,9,12- $\mathrm{I}_{3}-1,2$-closo- $\mathrm{C}_{2} \mathrm{~B}_{10} \mathrm{H}_{9}$ and $4 \%$ of higher iodinated ortho-carboranes. Almost all of the excess iodine, 95\%, could be effectively recovered from the mixture by sublimation under reduced pressure as a crystalline solid, avoiding its quenching with sodium metabisulfite and 75 allowing further re-utilisation. The residual solid was recrystallized from 1:1 ethanol/water, giving pure 1 in a high yield. The ${ }^{11} \mathrm{~B}\left\{{ }^{1} \mathrm{H}\right\}$ NMR shows a pattern 2:2:4:2 in which the resonances at higher and lower field do not split in the ${ }^{11} \mathrm{~B}-\mathrm{NMR}$


90

Fig. 1. Perspective view of the asymmetric unit of 1 with $30 \%$ ellipsoids. Selected bond lengths ( $\AA$ ): C(1)-C(2) 1.599(10), C(21) - C(22) 1.611(12), B-I 2.139(10) - 2.164(8) ̊. 
confirming that four boron atoms have one exocluster iodine. The

$95{ }^{1} \mathrm{H}$ NMR spectrum of 1 reveals a singlet at $5.57 \mathrm{ppm}$. assigned to the two C-bonded $\mathrm{H}$ atoms, ca. $2 \mathrm{ppm}$. to high frequency relative to that in 1,2-closo- $\mathrm{C}_{2} \mathrm{~B}_{10} \mathrm{H}_{12}$, suggesting greater protonic character for these $\mathrm{H}$ atoms in the tetraiodo species. To confirm the structure 15 of $\mathbf{1}$, colourless crystals were grown by the slow evaporation of a

100 hexane/dichloromethane solution and a single-crystal $X$-ray diffraction analysis ${ }^{10}$ (Figure 1) was undertaken.

The synthesis of $\mathbf{1}$ had been reported in low yield by using chlorinated solvents and long workup procedures. ${ }^{6 b, 11}$ Therefore the160 preparation and isolation of $\mathbf{1}$ described here is a much more

105 convenient and efficient route.

To prove the versatility of the method, C-alkyl- and Caryl- substituted ortho-carboranes were iodinated under similar conditions. Slightly shorter reaction times were needed for the 165 same degree of substitution. After heating 1-R-1,2-closo-

$110 \mathrm{C}_{2} \mathrm{~B}_{10} \mathrm{H}_{11}(\mathrm{R}=\mathrm{Me}, \mathrm{Ph})$ with $\mathrm{I}_{2}$ at $270 \pm 2{ }^{\circ} \mathrm{C}$ for 3.5 hours in a sealed tube, the corresponding 1-R-8,9,10,12-I $\mathrm{I}_{4}-1,2-$ closo$\mathrm{C}_{2} \mathrm{~B}_{10} \mathrm{H}_{7}(\mathrm{R}=\mathrm{Me}, 2 ; \mathrm{Ph}, 3)$ derivatives were selectively produced in high yields $(>75 \%)$. It is noteworthy that in the iodination of 1$\mathrm{Ph}-1,2$-closo- $\mathrm{C}_{2} \mathrm{~B}_{10} \mathrm{H}_{11}$, only $\mathrm{B}-\mathrm{H}$ vertices from the cluster have 170

115 been activated, and in no case C-I substitution in the aromatic ring has been observed. These data have been obtained by ${ }^{1} \mathrm{H}$ or ${ }^{13} \mathrm{C}\left\{{ }^{1} \mathrm{H}\right\}$ NMR spectroscopy. To unambiguously prove such reactivity, good crystals of 3 were grown by slow evaporation of 175 a hexane/dichloromethane solution and X-ray analysis was 120 undertaken (Figure 2). ${ }^{12}$

125

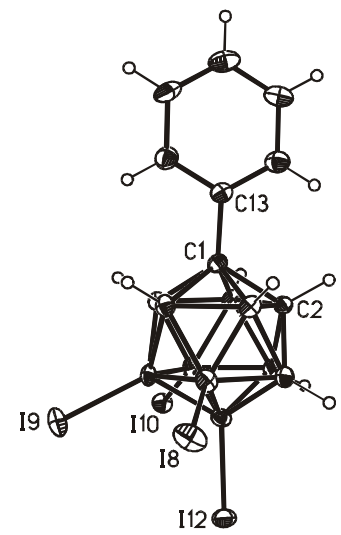

Fig. 2. Perspective view of 3 with $30 \%$ ellipsoids. Selected bond lengths 195

135 (̊): C(1)-C(2) 1.659(9), C(1) - C(13) 1.501(9), B-I 2.147(7) - 2.155(7)

$\AA$.

The C-disubstituted counterparts, 1,2- $\mathrm{R}_{2}-1,2$ - closo- $\mathrm{C}_{2} \mathrm{~B}_{10} \mathrm{H}_{10}(\mathrm{R}=$ $\mathrm{Me}, \mathrm{Ph}$ ) were iodinated in a parallel way and the crude products obtained were analysed by ESI-MS. The 1,2- $\mathrm{Ph}_{2}-1,2$-closo-

$140 \mathrm{C}_{2} \mathrm{~B}_{10} \mathrm{H}_{10}$ achieved tetraiodination rather selectively after 3.5 hours too, whereas the 1,2- $\mathrm{Me}_{2}-1,2$-closo- $\mathrm{C}_{2} \mathrm{~B}_{10} \mathrm{H}_{10}$ showed to be more susceptible to electrophilic substitution and only 2.5 hours 205 were enough for completion of the reaction. It agrees with the theoretical ${ }^{13}$ and experimental results ${ }^{14}$ reported by Lipscomb that

145 electron donating methyl groups bonded to the $\mathrm{C}_{\text {cluster }}$ atoms cause a rather uniform increase in electron density on the $\mathrm{B}$ atoms while keeping inalterable the sequence of substitution.

Once the feasibility of the method to selectively produce tetraiodinated ortho-carboranes has been proven, further 150 experiments regarding temperature have been done to tune the degree of substitution. Increasing the temperature, and even the reaction time to several days, did not produce satisfactory results in terms of selectivity, as mixtures of highly iodinated orthocarboranes were always generated. Nevertheless, by limiting the temperature to $170 \pm 2{ }^{\circ} \mathrm{C}$, a reagents mixture of 1,2 -closo- $\mathrm{C}_{2} \mathrm{~B}_{10} \mathrm{H}_{12}$ and $\mathrm{I}_{2}$ in 1:10 ratio produced after 4 hours in the oven a crude product containing 9,12- $\mathrm{I}_{2}-1,2$-closo- $\mathrm{C}_{2} \mathrm{~B}_{10} \mathrm{H}_{10}$ (85\%), 8,9- $\mathrm{I}_{2}-1,2-$ closo- $\mathrm{C}_{2} \mathrm{~B}_{10} \mathrm{H}_{10}(13 \%)$ and 8,9,12- $\mathrm{I}_{3}-1,2-$ closo- $\mathrm{C}_{2} \mathrm{~B}_{10} \mathrm{H}_{9}(2 \%)$, based on ${ }^{1} \mathrm{H}$ and ${ }^{1} \mathrm{H}\left\{{ }^{11} \mathrm{~B}\right\}$ NMR spectroscopy.

0 As a conclusion, our targeted synthesis and processing of tetraiodinated ortho-carboranes with a solvent-free, high yield, fast, clean and regioselective method has been achieved. Additionally, the procedure does not require any futher solvent-based workup and excess of iodine is recovered and re-utilized. Work is now underway to study the reported iodinated compounds as X-ray contrast agents on methyl methacrylate poymerization for bone cements and as building blocks for supramolecular chemistry.

\section{Notes and references}

1 (a) R. Noyori, Chem. Commun., 2005, 1807. (b) M. Avalos, R. Babiano, P. Cintas, J. L. Jiménez and J. C. Palacios, Angew. Chem. Int. Ed., 2006, 45, 3904. (c) M. Jansen and J. C. Schön, Angew. Chem. Int. Ed., 2006, 45, 3406.

2 R. D. Rogers and K. R. Seddon, Science, 2003, 302, 792.

3 (a) G. Kaupp Top. Curr. Chem., 2005, 254, 95. (b) K. Tanaka and F. Toda, Chem. Rev., 2000, 100, 1025. (c) G. W. V. Cave, C. L. Raston and J. L. Scott, Chem. Commun., 2001, 2159. (d) G. Rothenberg, A. P. Downie, C. L. Raston and J. L. Scott, J. Am. Chem. Soc., 2001, 123, 8701. (e) V. P. Balema, J. W. Wiench, M. Pruski and V. K. Pecharsky, Chem. Commun., 2002, 1606. (f) V. P. Balema, J. W. Wiench, M. Pruski and V. K. Pecharsky, J. Amer. Chem. Soc., 2002, 124, 6244 .

4 Ell P. J.; Gambhir, S. In Nuclear Medicine in Clinical Diagnosis and Treatment, 3rd edition Elsevier 2004.

5- S.-B. Yu and A. D. Watson, Chem. Rev., 1999, 99, 2353.

1856 (a) R. R. Srivastava, D. K. Hamlin and D. S. Wilbur, J. Org. Chem., 1996, 61, 9041; (b) PCT Int. Appl., WO9526353, 1995. Eur. Pat. Appl., EP0700918, 1996.

7 J. Li, C. F. Logan and M. Jones, Jr., Inorg. Chem., 1991, 30, 4866.

8 A. S. Batsanov, M. A. Fox, J. A. K. Howard, A. K. Hughes, A. L. Johnson and S. J. Martindale, Acta Cryst., 2003, C59, o74.

9 (a) G. Barberà, F. Teixidor, C. Viñas, R. Sillanpää and R. Kivekäs, Eur. J. Inorg. Chem., 2003, 1511; (b) G. Barberà, F. Teixidor, C. Viñas, R. Sillanpää and R. Kivekäs, Inorg. Chem., 2006, 45, 3496.

10 Crystal data. 1: $\mathrm{C}_{2} \mathrm{H}_{8} \mathrm{~B}_{10} \mathrm{I}_{4}, M=647.78$, monoclinic, space group $P 2{ }_{l} / c$ (no. 14), $a=15.0422(5), b=14.8814(5), c=14.3581(5) \AA$, $\beta=$ $110.378(2)^{\circ}, U=3012.90(18) \AA^{3}, Z=8, D_{\mathrm{c}}=2.856 \mathrm{~g} \mathrm{~cm}^{-3}, \mu(\mathrm{Mo}-$ $\mathrm{K} \alpha)=8.235 \mathrm{~mm}^{-1}, T=173 \mathrm{~K} . F(000)=2256.18481$ reflections measured, 6563 unique $\left(R_{\text {int }}=0.0581\right) . R 1\left(F_{\mathrm{o}}\right)=0.0417\left[w R 2\left(F_{\mathrm{o}}^{2}\right)=\right.$ $0.0855]$ with a goodness-of-fit of 1.049 .

20011 L. I. Zakharkin, V. I. Stanko and A. I. Klimova, Izv. Akad. Nauk SSSR, Ser. Khim., 1966, 11, 1946.

12 Crystal data. 3: $\mathrm{C}_{8} \mathrm{H}_{12} \mathrm{~B}_{10} \mathrm{I}_{4}, M=723.88$, monoclinic, space group $P 21 / n$ (no. 14), $a=10.0569(4), b=15.2555(5), c=13.0206(5) \AA$ A, $\beta=$ 99.686(2) ${ }^{\mathrm{o}}, U=1969.18(13) \AA^{3}, Z=4, D_{\mathrm{c}}=2.442 \mathrm{~g} \mathrm{~cm}^{-3}, \mu(\mathrm{Mo}-\mathrm{K} \alpha)$ $=6.314 \mathrm{~mm}^{-1}, T=173 \mathrm{~K}, F(000)=1288.11228$ reflections measured, 4181 unique $\left(R_{\text {int }}=0.0432\right) . R 1\left(F_{\mathrm{o}}\right)=0.0390\left[w R 2\left(F_{\mathrm{o}}{ }^{2}\right)=\right.$ 0.0744 ] with a goodness-of-fit of 1.053 .

13 (a) M. D. Newton, F. P. Boer and W. N. Lipscomb, J. Am. Chem. Soc., 1966, 88, 2353. (b). F. P. Boer, J. A. Potenza and W. N. Lipscomb, Inorg. Chem., 1966, 5, 1301.

14 J. A. Potenza and W. N. Lipscomb, Inorg. Chem., 1966, 5, 1483. 
